\title{
Desiccation crack in lime-treated silty clay: Experimental evaluation and constitutive interpretation
}

\author{
Nicolas Poncelet ${ }^{1, *}$ and Bertrand François ${ }^{1}$ \\ ${ }^{1}$ Université Libre de Bruxelles, BATir Department, Brussels, Belgium
}

\begin{abstract}
The present work investigates the desiccation effects on a lime-treated clayey silt. Original experimental techniques have been developed to control suction conditions (with osmotic technique) and to track volume variations and cracks occurrence upon drying. Free and constrained dryings are performed to evaluate the shrinkage potential (for free drying) and the conditions of desiccation crack triggering (upon constrained drying). Also, indirect tensile tests and uniaxial compression tests are carried out to evaluate the strength at various suctions. Those investigations have been performed on natural and lime-treated clayey silt in order to emphasis the role of the lime treatment in the triggering and/or mitigation of the cracking process. At the end, generalized effective stress framework with an effective stress parameter $\chi$ calibrated according to a power law is used to provide a constitutive interpretation of the occurrence of desiccation cracks in relation with the water retention properties, the soil stiffness, the tensile strength and the geometrical constraints of the soil samples. For the used compacted materials, it is demonstrated that the lime treatment postpones the occurrence of desiccation cracks and so, plays a favourable role in the stabilization of soft soils subject to drying.
\end{abstract}

\section{Introduction}

Lime treatment of clayey soil is a well-established technique to improve the engineering properties of soils that have initially poor mechanical properties. Lime treatment influences the soil behaviour on two different time scales. First, lime quickly reacts with clay by modifying its structure, and allowing the clay minerals to merge and form larger aggregates. The second effect is a soil stabilization linked to long-term pozzolanic reactions [5].

In literature, past researches have been conducted to investigate the physical processes of desiccation cracking of intact, compacted or slurry soils, from experimental or theoretical point of views $[2,6,7,9,10,12]$. Desiccation cracking mainly occurs because the shrinkage is partially or totally constrained by various effects (Kodikara \& al., 2000). Upon drying, the suction increases and induces an internal (effective) stress in the materials that tends to produce shrinkage. In order to restrain this shrinkage, a tensile stress is developed in the materials, opposed to the compressive effective stress. When this tensile stress overpasses the tensile strength, cracks occur.

On one hand, lime-treatment reduces the shrinkage potential but on the other hand, it increases the soil stiffness that, in turn, increases the generated tensile stress induced by deformation constrains. Finally, limetreatment also increases tensile strength. At the end, limetreatment plays antagonist roles and the coupled behaviour including shrinkage potential, soil stiffness and tensile strength must be evaluated separately in order to assess the beneficial or detrimental effects of the limetreatment on desiccation cracking.

This paper presents first the constitutive framework using the concept of generalized effective stress for unsaturated soils. In such a way the governing parameters are highlighted. In order to determine those parameters, a series of experimental apparatus have been developed and are presented in the next section. Finally, experimental results are presented and interpreted in the light of the developed constitutive framework and conclusions are drawn in regards with the beneficial effect of lime treatment on the reduction of crack occurrence.

\section{Constitutive framework}

In this study, generalized effective stress for unsaturated soil is used with the effective stress parameter $\chi$ expressed according to a power law of the degree of saturation [1]:

$$
\sigma_{i j}^{\prime}=\sigma_{n e t, i j}+\left(S_{r}\right)^{\alpha} \cdot s \cdot \delta_{i j}
$$

where $\sigma^{\prime}$ is the generalized effective stress, $\sigma_{\text {net }}$ is the net stress, $\mathrm{s}$ is the applied suction and $\mathrm{S}_{\mathrm{r}}$ is the degree of saturation that can be related to suction through the water retention curve for which a Van Genuchthen expression is used [11]:

$$
S_{r}=\left[1+\left(\frac{s}{P_{r}}\right)^{n}\right]^{\left(1-\frac{1}{n}\right)}
$$

\footnotetext{
Corresponding author: nponcele@ulb.ac.be
} 
where the saturation degree $S_{r}$ is a function of suction $s$ and two parameters (n and $P_{r}$ ).

As a first approach, the stress-strain behaviour is considered elastic, with the elastic stiffness expressed as a function of the suction, through non-linear elasticity:

$$
d \varepsilon_{i j}=C_{i j k l} \cdot d \sigma^{\prime}{ }_{k l}
$$

where $\varepsilon$ is the strain and $C$ the compliance matrix, governed, classically, by Young modulus and Poisson ratio. The Young modulus is a function of suction, through non-linear elasticity.

Upon free shrinkage, the deformation is free of external (net) stress and the strain is fully induced by the variation of effective stress, linked to the change of suction and degree of saturation. According to the elastic law, the strain increment vector can be expressed as:

$$
\left(\begin{array}{l}
d \varepsilon_{1} \\
d \varepsilon_{2} \\
d \varepsilon_{3}
\end{array}\right)=\frac{1}{E(s)}\left(\begin{array}{ccc}
1 & -v & -v \\
-v & 1 & -v \\
-v & -v & 1
\end{array}\right)\left(\begin{array}{l}
d\left[\left(S_{r}\right)^{\alpha} \cdot s\right] \\
d\left[\left(S_{r}\right)^{\alpha} \cdot s\right] \\
d\left[\left(S_{r}\right)^{\alpha} \cdot s\right]
\end{array}\right)
$$

For constrained shrinkage, the deformation is fully blocked in both horizontal directions (directions 1 and 2) while the vertical direction (direction 3 ) is free to shrink. Those restrictions induce an increase of external (net) stress according to the elastic law:

$$
\left(\begin{array}{c}
0 \\
0 \\
d \varepsilon_{3}
\end{array}\right)=\frac{1}{E(s)}\left(\begin{array}{ccc}
1 & -v & -v \\
-v & 1 & -v \\
-v & -v & 1
\end{array}\right)\left(\begin{array}{c}
d\left[\sigma_{n e t, 1}+\left(S_{r}\right)^{\alpha} \cdot s\right] \\
d\left[\sigma_{n e t, 1}+\left(S_{r}\right)^{\alpha} \cdot s\right] \\
d\left[\left(S_{r}\right)^{\alpha} \cdot s\right]
\end{array}\right)
$$

In equation (5), the unknowns are $d \sigma_{\text {net, }, 1}, \mathrm{~d} \sigma_{\text {net, } 2}$ and $\mathrm{d} \varepsilon_{3}$, that can be deduced from the elastic parameters and the retention properties (link between suction and degree of saturation).

\section{Materials and experimental methods}

\subsection{Soil properties}

A silty clay soil (CL, according to the Unified Soil Classification System - USCS) that has been used for the construction of a prototype dike in the South of France has been chosen for this study. Its index properties are: liquid limit $\left(\mathrm{w}_{\mathrm{L}}\right)=33,6 \%$; plasticity index (IP) $=14.8 \%$. The clayey fraction represents $22 \%$, the silty one about $60 \%$ and the sandy one about $18 \%$. This material has shown its relevance to be treated with lime, essentially due to its relatively large clay fraction. Optimum normal proctor conditions have been determined at $\mathrm{w}_{\mathrm{opt}}=15.5 \%$ and $\gamma_{\mathrm{d} \text {,opt }}$ $=17.6 \mathrm{kN} / \mathrm{m}^{3}$ for untreated soil and $\mathrm{w}_{\mathrm{opt}}=17.8 \%$ and $\gamma_{\mathrm{d} \text {,opt }}$ $=17.1 \mathrm{kN} / \mathrm{m}^{3}$ for soil treated soil with $2 \%$ of lime.

The water retention curves of both treated and untreated materials are reported in Fig. 1. They have been determined on small fragments of compacted soils (see compaction process in Section 3.2) and using the Van Genuchten model [11]. The parameters $n$ and Pr necessary to fit the results are given in Table 1 .
Table 1. Van Genuchten parameters for both untreated and treated soils

\begin{tabular}{c|c|c} 
& $P_{\mathrm{r}}$ & $\mathrm{n}$ \\
\hline Untreated soils & 120000 & 1.18 \\
\hline Treated soils & 75000 & 1.25
\end{tabular}

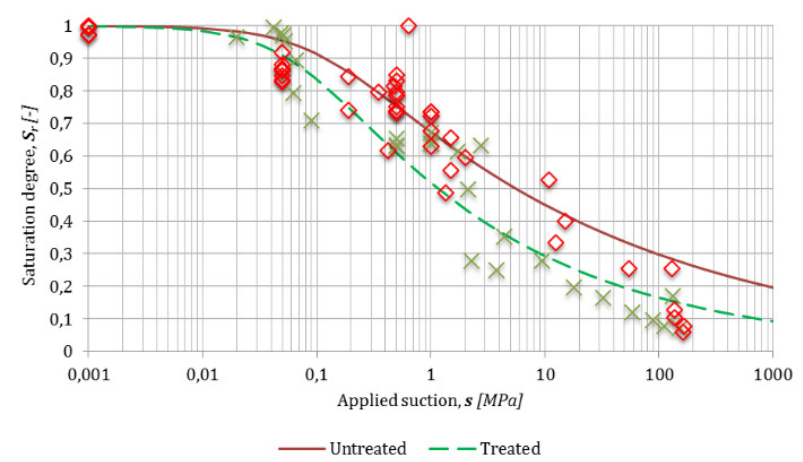

Fig 1. Water retention curve (WRC) of both treated and untreated soils

To obtain these results, osmotic technique is used to insure a fine control of the suction for suction lowest than $1 \mathrm{MPa}$. For greater suction, samples are dried under free air conditions during various lapses of time (from a couple of minutes to several hours) and then placed 24 hours in hermetically sealed containers to obtain a global homogenization of water distribution in the sample. They are then inserted in a dewpoint potentiometer to measure their total suction.

\subsection{Sample preparation}

For the soil preparation, the dry soil is mixed with the required quantity of water to reach an initial water content of $16 \%$ for untreated soil and $21.5 \%$ for treated soil. After wetting the soil at targeted water content, wet soil is sealed in plastic buckets during at least 24 hours to achieve homogeneous water content in the soil. Then, after addition of $2 \%$ of lime, the treated soil loose approximately $1.7 \%$ of water content to reach the targeted initial water content of $19.8 \%$. Treated soil is then sealed in a bucked during one hour before compaction.

In order to simulate the action of compacting machinery in the field, the kneading compaction [8] has been used for sample preparation. It is based on the use of a three kneading feet tool designed to fit with a CBR mold ( $15.24 \mathrm{~cm}$ diameter and $12.7 \mathrm{~cm}$ height) and mounted on a mechanical press. The total soil volume needed to realise a CBR sample is divided in five layers. Each of them is then compacted with an eight steps compaction sequence. The target values of the dry unit weight $\gamma_{\mathrm{d}}$ are respectively $1,71 \mathrm{~g} / \mathrm{cm}^{3}$ and $1,64 \mathrm{~g} / \mathrm{cm}^{3}$ for untreated and treated soil. To achieve this target density, the stress applied on the layers during each compaction step is equal to 0.45 and $0.65 \mathrm{MPa}$ respectively for the untreated and the treated soil. 
Finally, from CBR samples, three kinds of samples have to be extracted:

i. Rectangular samples (for free and constrained desiccations) of $140 \mathrm{~mm}$ length, $50 \mathrm{~mm}$ width and $15 \mathrm{~mm}$ height

ii. Cylindrical samples (for indirect tensile tests) of 36 $\mathrm{mm}$ diameter and $18 \mathrm{~mm}$ height.

iii. Cylindrical samples (for uniaxial compression tests) of $36 \mathrm{~mm}$ diameter and $72 \mathrm{~mm}$ height.

In order to avoid soil damaging during sample extraction from the CBR model and also to obtain precise sample dimensions, specimen have been milled with a milling machine controlled by computer.

\subsection{Suction control}

For our application, suction control by osmotic technique [3] has been selected as the most appropriate method to control the suction of the samples mainly for two reasons. On one hand, this technique offers a good precision in the suction control for the required range of applied suction (0 to $2 \mathrm{MPa}$ ). On the other hand, the time to reach suction equilibrium in the sample remains lower than 7 days that is the target curing time for all the tests on treated materials.

A specific osmotic device was developed to reproduce the drying process from one face of the specimen and possible deformation restriction on the other face. A solution of Poly-Ethylene Glycol (PEG) in various concentrations circulates in a circuit under a flat semipermeable membrane while the samples are installed on that membrane. In case of constrained shrinkage, a twodimensional truss with 122 pines realised in a single piece of aluminium is introduced on the top surface of the sample. Each pine has a diameter of $1.0 \mathrm{~mm}$ and a height of $2.0 \mathrm{~mm}$ (Fig. 2).
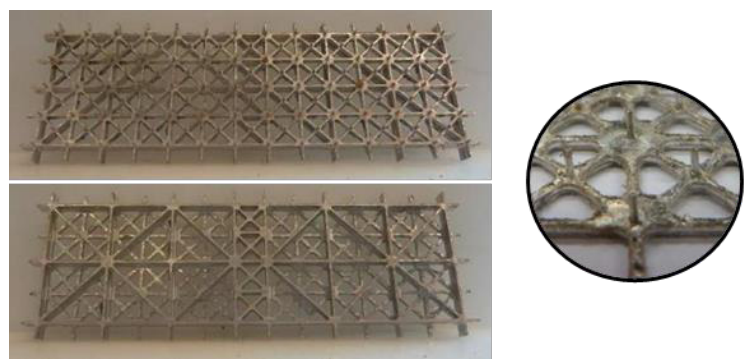

Fig. 2. Top and bottom view of the constrained shrinkage devise (CSD) (left) and zoom on the pines (right)

This system allows to constrain the horizontal strain at the base of the specimen while the vertical strain is remained free. The high density of pines allows to minimize the stress concentration on the soil around each pine during the constrained desiccation process. At the end, it was observed that the cracks initiate from the opposed side to the pines (the side submitted to drying) while the pine does not produce crack trigger due to a possible stress concentration.

In the case of uniaxial compression tests, samples are hermetically enclosed in a semi-permeable membrane.
The obtained system is directly submerged in a PEG solution.

When equilibrium is reached, within less than 7 days, the final mass is recorded and the dimensions are measured with a 3D scanner (Einscan-S Shining 3D). This full field measurement method is a fast procedure without contact with the sample and with good accuracy $(0.1 \mathrm{~mm})$.

\subsection{Experimental program}

The objective is to evaluate the shrinkage or swelling behaviour from as-compacted conditions to various targeted suction levels. Free and constrained swellings/shrinkages of untreated and treated soil specimen are monitored under various target suctions $(0$ $\mathrm{kPa}, 500 \mathrm{kPa}, 1000 \mathrm{kPa}$ and $1500 \mathrm{kPa}$ ). Under free conditions, the sample dimensions are measured with the 3D scanner while for constrained conditions, the occurrence of cracks is monitored visually. Also, compressive and tensile strength are evaluated respectively through uniaxial compressive tests and indirect tensile tests. In addition of the previous suction levels, the as-compacted state corresponding to a suction of $120 \mathrm{kPa}$ is also investigated during these testing procedures. For treated soils, the behaviour is characterized after 7 days of curing time. The curing takes place in parallel with the suction equilibration in the specimen.

\section{Results}

\subsection{Indirect tensile tests}

The tensile strength, determined from indirect tensile tests, is strongly affected by lime treatment and suction. Fig. 3 shows the evolution of the tensile strength as a function of the applied suction, for treated (after 7 days of curing time) and untreated specimen. As expected, tensile strength increases with suction in the case of untreated samples. However, this is not the case for the treated samples where the tensile strength oscillates around 90 $\mathrm{kPa}$, excepted for saturated specimen exhibiting a much lower tensile strength. We also observe a spreading of the results due to the variability of dry density (the kneading compaction process induces a slight heterogeneity in the obtained density).

\subsection{Uniaxial compression tests}

Fig. 4 presents the Young modulus obtained at the inflection point of the uniaxial compression curve respectively for untreated and treated samples. The start of the curve being affected by the progressive contact between the piston and the soil sample, the slope around the inflection point has been selected as the most representative value to represent the stiffness of the material. The inflection point provides the maximum slope of the curve and still concerns limited strain level (in the same range than the strains experienced by the material during drying). 


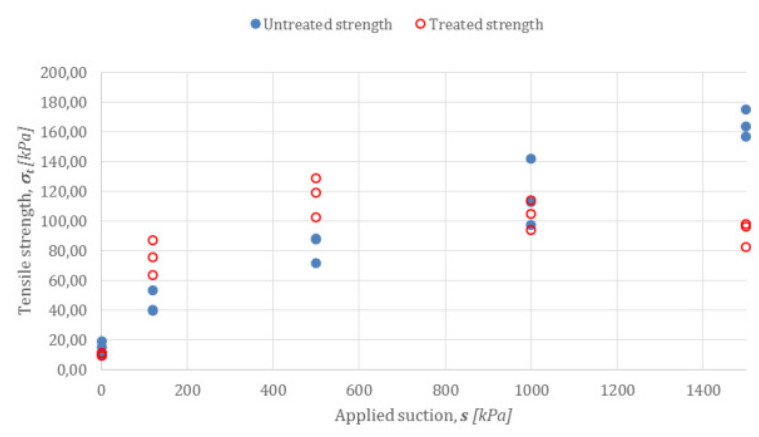

Fig. 3. Tensile strength $\sigma_{t}$ in function of the applied suction $s$

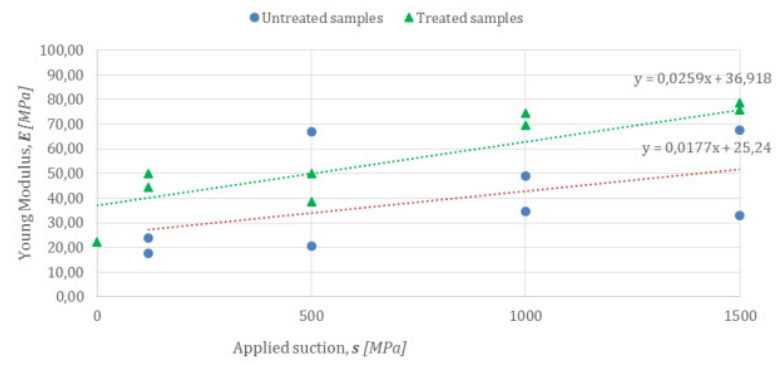

Fig. 4. Young modulus in function of the applied suction. Experimental measurements (points) and fitted linear evolutions (lines).

We may observe that the suction level has a significant impact on the Young modulus of both treated and untreated samples. The suction increase induces an increase of the Young modulus.

Fig. 5 presents the compressive strength of the treated and untreated samples subjected to the same range of suction. The increase of the suction induces an increase of the compressive strength for both treated and untreated samples.

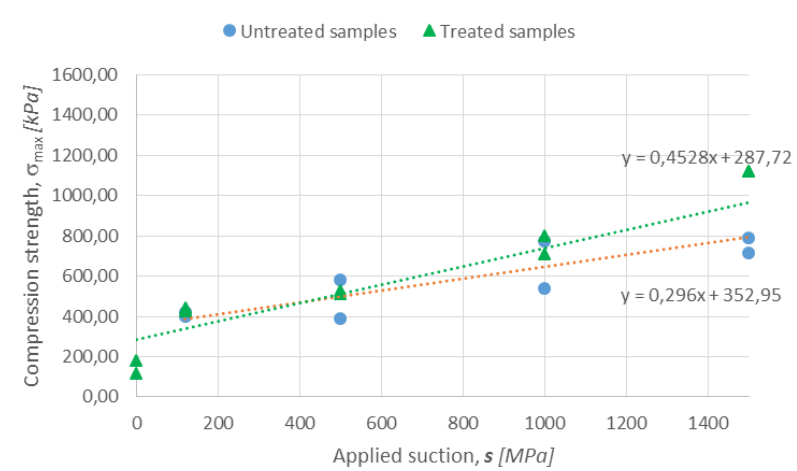

Fig. 5. Compressive strength in function of the applied suction. Experimental measurements (points) and fitted linear evolutions (lines).

\subsection{Free shrinkage}

With the 3D scanner, the volume of the samples was measured before and after suction application for free shrinkage of rectangular samples and cylindrical samples. Fig. 6 shows the obtained results. Lime-treatment reduces significantly the volume variations (swelling or shrinkage) of the specimen. For the "as-compacted" conditions (without any change of suction during 7 days), untreated soils shows no volume variation while treated soils exhibit a slight endogenous shrinkage, due to lime reaction.

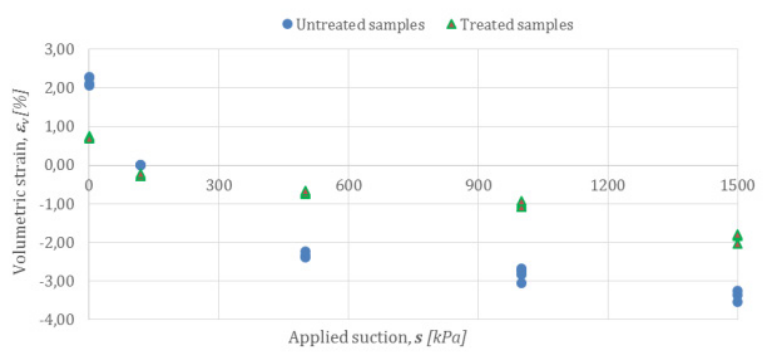

Fig. 6. Volumetric strain $\varepsilon_{\mathrm{v}}$ in function of the applied suction $s$ for both treated and untreated samples.

\subsection{Constrained shrinkage}

For constrained shrinkage, the deformation is restricted with the two-dimensional truss with pines introduced in the top surface of the samples. Possible cracks occurrence is observed visually. As summarized in Table 2, desiccation cracking occurs for the drying at a suction of respectively $1000 \mathrm{kPa}$ and $1500 \mathrm{kPa}$ on untreated and treated soils. A single crack develops perpendicularly to the larger direction of the specimen, approximately in the middle (Fig. 7).

Table 2. Visual observation of the cracks during the various

\begin{tabular}{|c|c|c|}
\hline \multirow{2}{*}{$\begin{array}{c}\text { Applied } \\
\text { suction }\end{array}$} & \multicolumn{2}{|c|}{ Tests } \\
\cline { 2 - 3 } & Untreated & Treated \\
\hline $0 \mathrm{kPa}$ & $x$ & $x$ \\
\hline As Compacted & $x$ & $x$ \\
\hline $500 \mathrm{kPa}$ & $x$ & $x$ \\
\hline $1000 \mathrm{kPa}$ & $\checkmark$ & $x$ \\
\hline $1500 \mathrm{kPa}$ & - & $\checkmark$ \\
\hline
\end{tabular}

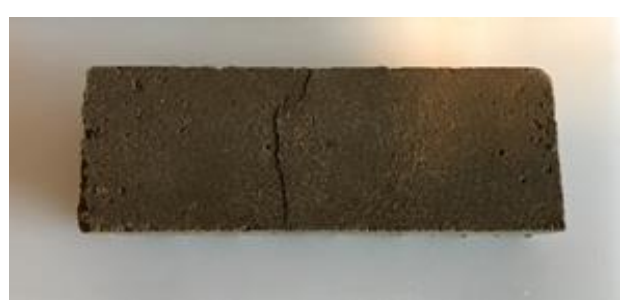

Fig. 7. Crack observed on the untreated sample subject to a suction of $1000 \mathrm{kPa}$

\section{Interpretations and discussions}

\subsection{Calibration of the $\alpha$ parameter}

The crack occurrence from a constitutive point of view can be analyzed from the effective stress framework as developed in Section 2. According to the approach developed by Gerard et al. (2015), it is possible to deduce 
the exponent $\alpha$ of the effective stress parameter in order to obtain the uniqueness of the failure criterion for any suction. The purpose being to obtain an unique failure criterion, the objective is to find the value of $\chi$, expressed as a function of $\mathrm{Sr}$, that allows to translate horizontally the corresponding Mohr circle at the ultimate stress state expressed in total stress on the failure criterion, expressed in effective stress.

The intrinsic strength is given by the strength upon saturated conditions $\left(\phi^{\prime}=34.5^{\circ}\right.$ and $\mathrm{c}=10.3 \mathrm{kPa}$ for untreated soils; $\phi^{\prime}=40.0^{\circ}$ and $\mathrm{c}=45.1 \mathrm{kPa}$ for treated soils) and the distance between saturated strength and strengths at different suctions is compensated by the product $(\mathrm{Sr})^{\alpha} \mathrm{s}$.

The best fit, in the sense of least square, to get the uniqueness of the failure criterion is obtained for $\alpha=3,6$ for untreated soils and $\alpha=2.74$ for treated soils. Figs. 11 and 12 shows the obtained alignment of the uniaxial compression failure circles in the effective stress reference.
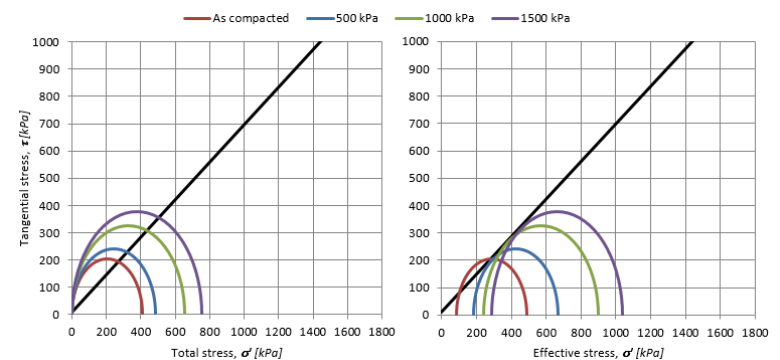

Fig. 11. Calibration of the function $\chi$ for untreated soil $(\alpha=$ 3.6) from uniaxial compression tests

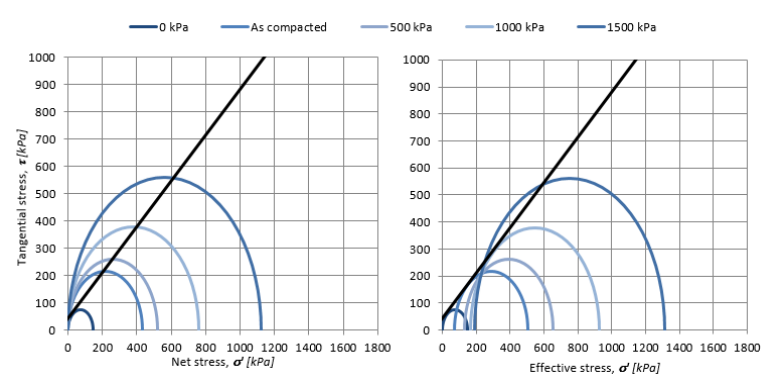

Fig. 12. Calibration of the function $\chi$ for treated soil $(\alpha=2.7)$ from uniaxial compression tests

\subsection{Free shrinkage}

When the expression of effective stress is known, we can use the elastic stiffness as a function of suction, as determined in Fig. 5, in order to reproduce the strain upon free shrinkage according to Eq. (3). Results are illustrated in Figs. 13 and 14, for untreated and treated specimen, respectively. We assume a Poisson coefficient of 0.2 for both untreated soils and treated soils. Note that for treated soil, an endogenous volumetric shrinkage (due to lime reaction with soil) of $0.5 \%$ (as observed experimentally for the as-compacted conditions) has been added in all predicted strains.
The matching between experimental results and model prediction is particularly noticeable because the model results consist exclusively in blind predictions. The elastic stiffness, measured on uniaxial compression tests, is able to reproduce the free shrinkage experienced upon drying process. In a sense, this matching confirms the validity of the $\alpha$ exponent determined independently.

\subsection{Constrained shrinkage}

Upon constrained shrinkage, Eq. (4) allows to deduce the tensile net stress as a function of suction while the tensile strength is reported in Figure 4. The comparison of the generated net stress and the strength allows to predict the suction leading to the triggering of desiccation cracking. This is done in Figs. 15 and 16 for untreated and treated soils, respectively.

Those developments reveal that, in theory, the tensile cracking induced by a desiccation process of the studied soil from as-compacted conditions, under constrained shrinkage, should occur at suctions around $500 \mathrm{kPa}$ for untreated soil and $1500 \mathrm{kPa}$ for treated soil. This is consistent with the experimental observations where we observed that cracks occurred between $500 \mathrm{kPa}$ and 1000 $\mathrm{kPa}$ for untreated specimen and between $1000 \mathrm{kPa}$ and $1500 \mathrm{kPa}$ for treated specimen (see table 2).

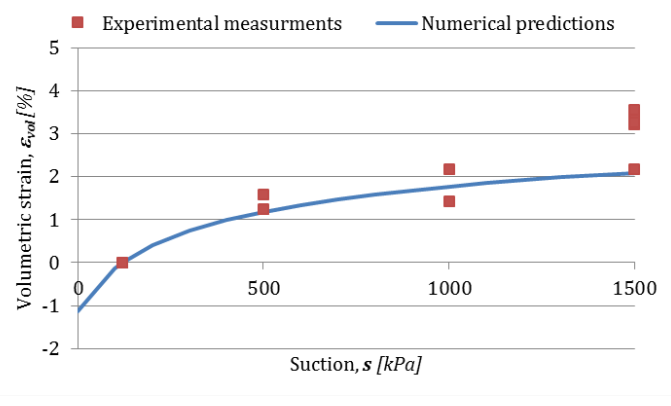

Fig. 13. Comparison between predicted and measured volumetric strains induced by different suctions under free shrinkage on untreated specimen.

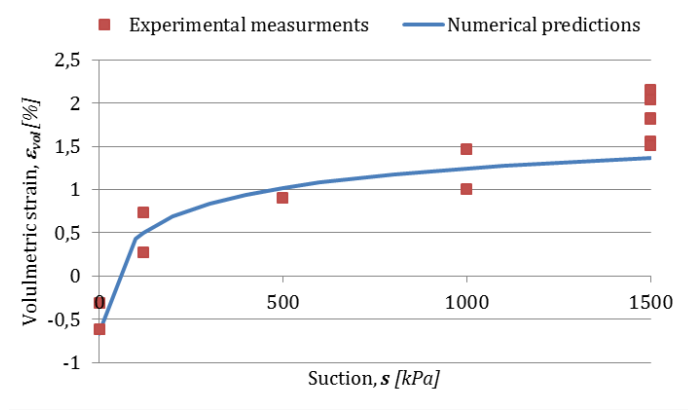

Fig. 14. Comparison between predicted and measured volumetric strains induced by different suctions under free shrinkage on treated specimen. 


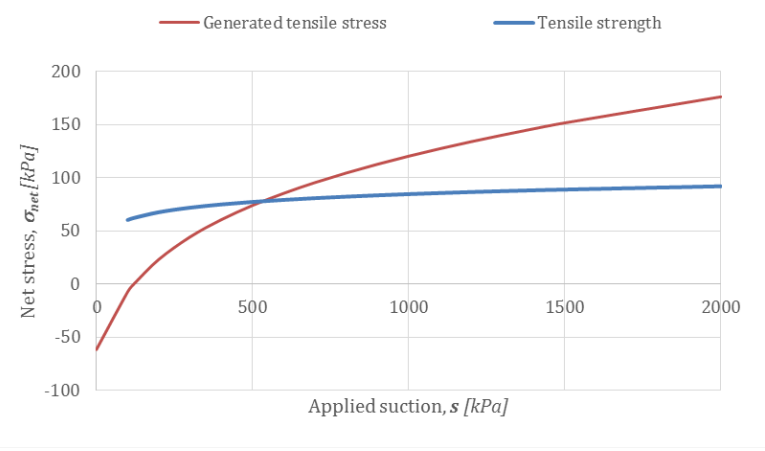

Fig. 15. Evolution of tensile stress and strength as a function of suction during constrained shrinkage of untreated specimen.

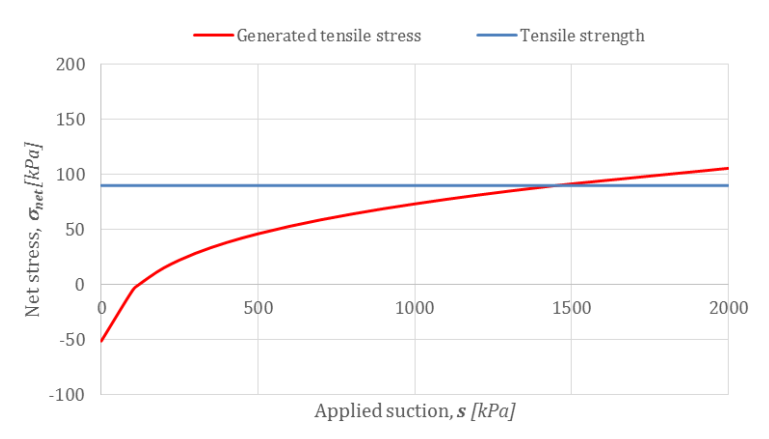

Fig. 16. Evolution of tensile stress and strength as a function of suction during constrained shrinkage of treated specimen.

\section{Conclusions}

Desiccation cracking occurs when the tensile stress overpasses the tensile strength of the material. Both parameters depend on suction. The tensile stress is induced by the constrained deformation upon drying. Consequently, it is a function of the soil stiffness that evolves during drying. The problem is highly coupled and the concept of unsaturated soil mechanics must be used to analyze the observed results. In the present study, effective stress framework for unsaturated soils is used with the $\chi$ parameter expressed as a power law of the degree of saturation.

In order to provide the required material parameters for the analysis, indirect tensile tests, uniaxial compression tests, free shrinkages and constrained shrinkages have been carried out on compacted untreated and lime-treated silty soils. It is demonstrated that the constitutive framework, using an effective stress formalism for unsaturated soils, is able to reproduce the experienced volumetric strain upon free shrinkage and crack occurrence upon constrained shrinkage.

For the tested soil, lime treatment (with $2 \%$ of lime) postpones the triggering of desiccation cracks. For a drying at $1000 \mathrm{kPa}$ of suction, untreated soil exhibits the development of a clear tensile crack while treated soil remains un-cracked until $1500 \mathrm{kPa}$ of suction upon the same constrained conditions. This is well reproduced by the constitutive model.

\section{References}

1. E.E. Alonso, N.M Pinyol, and A. Gens, Géotechnique, 63, 6, 463-478 (2013)

2. A. Corte and A. Higashi, Cold regions research and engineering lab Hanover NH. Experimental research on desiccation cracks in soil. (No. RR-66) (1964)

3. P. Delage, M. D. Howat, and Y. J. Cui, Eng. Geol., 50, 1-2, 31-48 (1998)

4. P. Gerard et al., Constr. Build. Mat., 95, 437-447 (2015)

5. D.N. Little. Stabilization of pavement subgrades and base courses with lime. Kendall/Hunt publication Company, Dubuque, IA, US (1995)

6. J. K. Kodikara, S. L. Barbour and D. G. Fredlund, Unsaturated soils for Asia, 90, 5809, 139 (2000)

7. J. M. Konrad and R. Ayad. Can. Geotech. J., 34, 6, 929-942 (1997)

8. P. Kouassi et al., Geotech. Test. J., 23, 1, 72-82 (2000)

9. C. J. Miller, H. Mi and N. Yesiller., J. Am.Wat. Res. Assoc., 34, 3, 677-686 (1998)

10. H. Péron, T. Hueckel, L. Laloui and L. Hu, Can. Geotech. J., 46, 10, 1177-1201 (2009).

11. M. T. Van Genuchten and D. R. Nielsen, Ann. Geoph., 3, 5, 615-628 (1985)

12. N. Yesiller, C. J. Miller, G. Inci and K. Yaldo, Eng. Geol., 57, 1-2, 105-121 (2000) 